\title{
Indirect Encountering Reflectively Analyzed
}

\author{
LESTER EMBREE
}

\section{Introduction}

There is a difference between the direct and the indirect encountering of things. The emphasis in the history of phenomenology, as in the rest of modern philosophy, has been on direct encountering. This is for epistemological reasons. When there is a conflict between what is indirectly encountered and what is directly encountered, the directly encountered is ultimately decisive. But at least in industrialized societies, there is acquaintance with vastly more things through indirect encountering than through direct encountering, and accordingly, for those who live in such societies, indirect encountering needs to be understood and appreciated.

In the following exposition, a clarification of what encountering is in general will first be attempted, some traditional doctrines will be objected to, and then the difference between direct and indirect encountering will be explored. Although there is extensive literature on this theme, this essay is not a work of scholarship, even critical scholarship — which could fill a book—but a modest phenomenological investigation that invites the reader to verify, correct, and extend it. If there is anything original about it, it concerns terminology, genre, and the secondary emphasis on thetic or positional components of believing, valuing, and willing. The approach will be phenomenological, which can alternatively be characterized as "reflective analysis" (see Embree). 
"Analysis" here signifies not only the distinguishing of components within the thing analyzed but also the result, which can be descriptive in particular as well as in general terms. It will be described in general terms here, with reference to particulars only as examples of general and specific universals. "Reflective" here first of all refers to a theoretical focusing on processes of encountering but immediately goes on to include things-as-encountered, so that what is analyzed has a twofold theme. (Actually, there is a fourfold theme when the participation of the "I" in the operational stratum of encountering is reflected on, but for present purposes that side of the situation reflected upon can be disregarded). And for present purposes, it will also not be necessary to leave the natural or, better, worldly attitude.

\section{Encountering in General}

The central concept of phenomenology is arguably that which is expressed by Husserl with the word "Erlebnis." Over the decades, this word has been translated into English in a number of ways. Some colleagues render it as "experience," while others use "mental process," and yet others use "lived experience." "Experience" underemphasizes the components of valuing and willing that are discernible in Erlebnisse, something that will be worked against below. "Mental process" seems for many too psychological. As for "lived experience," one can wonder about what an un-lived experience might be, i.e., what benefit the qualifier brings. "Lived experience" seems a translation of "expérience vécue," which the French have used to render Husserl's Erlebnis, but "lived experience" seems not to connote the subjectivity and process that the rendering of the French expression with "lived through experience" or "living experience" might better convey. 
Against the mentioned expressions in English for the concept expressed by Husserl's Erlebnis, I urge instead the English word "encounter," or better, "encountering." This is because the components of valuing and willing but also of believing, in broad significations, can more easily be connoted and can also be used to specify the generic term. Thus some encounterings are "valuational encounterings" in which liking, disliking, or apathy about something predominates, others are "practical or volitional encounterings" in which there is willing for, willing against, or being volitionally neutral toward the continued or inactual existence of something predominant, and yet others are-to use Husserl's word-“doxic encounterings" in which there predominates believing in, disbelieving in, or skeptical neutrality about something.

In addition to the inclusion of what might be called in general the thetic or positional components just listed, encounterings can also include experiential components of perceiving, remembering, and expecting of real things, and even the experiencing of ideal things such as concepts and universal essences. It has been traditional in phenomenology to emphasize the stratum of what can in general here be called "experiencing," something that fosters and benefits from rendering Erlebnis as "experience," but—again—-the rendering of it as "encountering" can help remind us to include the components of believing, valuing, and willing.

Correlative to the mentioned components within encounterings, things-as-encountered can be reflectively discerned and described with respect to how they are experienced, i.e., asperceived, as-remembered, and as-expected or as-ideally-intended, as well as with respect to how they are posited, i.e., as-believed-in, as-valued, and as-willed. In the latter respect, things can be willed for their own sake, which is to say as ends, and they can be willed for the sake of other things, which is to say as means, and then one can distinguish the intrinsic and extrinsic uses that things-as-willed can have. In analogous fashion, one can discern the intrinsic and extrinsic values 
that things-as-valued have, and even intrinsic and extrinsic belief characteristics that things-asbelieved-in have, e.g., as effects and causes.

These terms may become clearer when examples are related to them in what follows.

\section{Direct and Indirect Encounterings Contrasted}

As part of the effort to get a permit for some work on my house, I recently obtained a copy of a map and floor plan from the permitting agency of my city. It seems to show what one might see from some position above this property, with the roof of the house and the trees on the land removed. It has lines and gives distances for the fence, the street, and the walls around and between the rooms within the house. The direction of north is also indicated. It is in black and white and many things such as windows, furniture, trees, and grass are not depicted. I have no doubt that it is proportionally accurate about the area and structure.

This map is a kind of "pictorial representation" of my house and the land attached to it. On the basis of seeing it, I can experience my house in a somewhat unusual way. This is a case of indirect experiencing to begin with, and upon reflective analysis, it can be seen to have two strata, one a seeing of the paper with lines on it immediately before me, and on that basis, another experiencing of the layout of my house and land. More properly put, I encounter the depiction, and on the basis of encountering it, I encounter my house, but indirectly rather than directly as is usual.

What else does reflective analysis disclose in such a case? To begin with, I not only see

the sheet of paper with lines, words, and numbers written on it, but I also believe in it as a physical thing on the desk before me and value it positively as an accurate and indeed fascinating 
representation. It also has practical use for me and my workmen in showing where work is allowed by the city authorities to be done.

But what is represented by this depiction is also encountered. The first thing for me was to trace with my eyes the routes through the building from the front door through the parlor to the kitchen and dining room and then to the bedrooms and finally out the back door to the yard. These routes are practical. To some extent they are experienced memorially but they are also experienced in a fictive way that is as much expectational as perceptual and memorial, no doubt because it is a matter of what is deeply familiar. Part of the represented familiar house plan is its comfortableness, which is to say how it is positively valued by me. It is conceivable that somebody not familiar with these things might negatively value some aspect or other, say how the second bathroom is rather close to the parlor.

The infrastratum of this encountering is predominantly visual but also secondarily tactual, as I trace or am conscious of being able to trace with my finger on the depiction how one might move about within or around this building that I live in. But when not reflectively distinguishing and analyzing this infrastratum, it is the depicted place that is thematic. That it is a depicted place is, one can well say, "overlooked" and there is no explicit consciousness that the encountering is indirect or representational. What is different from usual is, as mentioned, the point of view high above the property and the omission of the roof and trees.

\section{Against Traditional Representationism}

There is a traditional account of experiencing that still deserves to be denounced now even over a century after Husserl's Logische Untersuchungen. This is the account whereby what one directly experiences even in perceiving and remembering are "ideas," as John Locke called 
them, which are "in" one's mind and are different from the realities themselves. This account can be opposed by means of reflective analysis, which shows no difference between, to begin with, what one directly experiences and the thing directly experienced. It is true for perceived physical things that one aspect, such as the front, is always presented while other aspects, including the back and the inside are appresented, but the relation between the presented and the appresented is not the alleged relation between the idea and the reality it allegedly represents, if for no other reason than that the appresented can be made presented by moving around or looking inside the physical thing, while there is never direct access to the external realities in the traditional representationalist account.

The traditional representationalist account may then again stem from how the appearances of physical things change as the distance between them and our sense organs, e.g., our eyes, changes. Then the visual appearances get larger or smaller as we get closer or further from the thing, but we nevertheless perceive the physical thing through them and it does not change its physical size. (Incidentally, phenomenology is not confined to appearances but is about ALL things - in the signification whereby anything can be a thing - that are or are able to be presented.)

It may be that the traditional representationalist account is most attractive when it comes to understanding memory. I had a dog when I was a boy and can remember clearly a time over 60 years ago when he ran down the street yelping excitedly to greet me on my return from somewhere, probably from school. Some might say that there must be a little picture, even a sort of little movie or video, in my mind as an immediate object in the now when I fondly remember Skipper on that occasion. It may also be that ideas are then conceived like words so that linguistic reference to objects might accomplish the reaching into the past that- 
phenomenologically - the intentiveness of an operation of remembering actually does. In any case, the problem with the traditional representationalist account is that upon reflection what I find is the operation of remembering going on in the now of my mental life and, correlatively, its intentional object, the excited dog, way back when, some sixty years ago, and nothing in between, no picture moving or not, no word, no memory image.

Another possible source for the representationalist account of recollection and perception (and one could extend it to expectation easily enough) is that the description of indirect experiencing is generalized to it so that all experiencing and thus encountering is considered indirect or representational. I do have a photo of Skipper in which he is depicted sitting with great dignity on a sofa he is not supposed to be on. Upon reflective analysis I can discern the infrastratum of my encountering that is the seeing of a small, flat, and multi-colored piece of paper, and on that basis, the memorial experiencing of my dog on the sofa long ago. In such a case, I normally just encounter my dog without any explicit consciousness that I do so on the basis of seeing this photograph. The infrastratum and the representiveness of the photo are overlooked. But if perception or recollection are like that, then I can reflectively distinguish two strata in them that I can describe with respect to the encountering of an object through a photograph. But I cannot do that with the remembering of Skipper. Remembering, expecting, and perceiving are not stratified like that.

So much in the way of challenging the traditional representationalist account.

\section{Continuing the Reflective Analysis}

The cases of the architectural drawing of my house and the photograph of my dog belong to the species of indirect encountering that can best be called pictorial encountering. This 
characterization emphasizes the experiential infrastratum, but I hope that my sketch at least of remembering Skipper with and without the photograph intimates how I loved him and hence he had positive value for me. Beyond that, I can mention his role as a companion, which I later came to understand that my mother considered some protection of me as a child- he was a very protective dog as I now recall—which was something practical and volitional at least for her, while for me he was useful simply for having fun together, and of course he was a psychophysical reality undoubtedly believed in by both of us.

There are two other so-to-speak pure types of indirect experiencing. One occurs through words and the other through indications. I hope that the serious reader of the present, mostly descriptive, remarks does not follow along blindly but tries reflectively to observe whether the things I have been talking about are as I say they are. For example, are believing, valuing, and willing, in broad significations, distinguishable components within encounterings? (Incidentally, I include the qualification "in the broad signification" because such components are discernable not only in operations in which an "I" is actively or passively engaged, but also in habitual and even automatic encounterings, in what Husserl called sekondär and primär Passivität.)

Then again, do believing, valuing, and willing, in broad significations, have positive, negative, and neutral modalities? Can one find then nine clear examples ranging from the positive believing in the chair perceived across the room, through an attempt to prevent getting wet by using an umbrella in the rain, to apathy concerning the outcome of some sports competition? And, moreover, are perceiving, remembering, and expecting distinguishable according to whether their objects are in the now, the past, or the future of the encounterings of them, and do they not share being directly intentive to these objects? 
Reflecting on this brief exercise, one should be able to discern the hearing of sounds or the seeing of marks, the thinking of the significations they convey, and the things that are what the thus significant expressions refer to. This is then another species of indirect encountering. In it, the perceiving and thinking in which the expression is constituted are normally overlooked and what one then thematizes are the things referred to, but even then they are not thematized asthings-referred-to. Only with some reflective analysis does one recognize what reading or hearing about things involves in the way of stratification. Rather, in hearing or reading about things, one simply encounters the things REFERRED TO and overlooks the believing in, liking and/or disliking, and even the becoming inclined to support or oppose their happening, or at least this is how things are for serious texts. Fictional literature is another somewhat different case that can be ignored here. And this second species of indirect encountering can be called "linguistic encountering," provided that the use of artificial language, e.g., that of mathematical symbols, is also considered language.

There is a third species of indirect encountering, which can be called "indicational encountering." I had a colleague at a university where I used to teach whose schedule more or less overlapped mine and with whom I enjoyed chatting about various events in university life and the wider world. On the way to my office I habitually came out of the elevator, walked around the corner, and looked to see if there was a light under his door. If there was, it was a rather reliable indication that he was there and I would usually knock on his door and have a gossip.

Now, the light under the colleague's door is not a verbal expression. Also, it does not resemble what it represents like a photograph does. Nevertheless, upon reflective analysis I can find the same kind of stratification that I find in linguistic and pictorial encountering. There is the 
perceiving of the light under the door and on that basis there is the encountering of the colleague in his office. Pictorial and indicational encountering differ from linguistic encountering in not having any significations necessarily involved and they differ from one another in how reflection can disclose resemblances between the depiction and the thing depicted, while my colleague, for example, does not resemble a stripe of light shining under a door.

This analysis has attempted to focus on simple cases, but plainly there are pure and mixed compounds. In a purely linguistic compound, one talks, understands, hears, or writes about a linguistic representation and there is then a linguistic representation of a linguistic representation. A pictorial representation of a pictorial representation is equally possible. As for mixed compounds, there can be a photograph of me peering down the hall at the light under my friend's door that is described in words and thus a depiction of a case of indicational encountering can be encountered linguistically. To recognize that such complexities need not be static, one need only consider encountering through film and video, where things are indirectly encountered together on the basis of words, pictures, and music indicating moods. And, once again, such encountering always has reflectively discernible components of believing, valuing, and willing within it.

Let me conclude with reference back to my opening remark. For the Bushmen of the Kalahari, for example, at least before civilization reached them and they were still innocent of written materials, photography, radio, and television, it could have been that indirect encountering occurred only through speech, animal tracks, perhaps some scratchings in the dirt, and of course the appresented mental lives of other human and non-human animals; but for people in industrialized societies the overwhelming bulk of acquaintance with things in the world is through indirect encountering via books and magazines, radio, film, and television, and this is 
why it is worth attempting a reflective analysis such as this, which can of course be corrected and refined through further reflective analysis. And, I might add, indirect encountering is far more prone to error and deception than direct encountering.

\section{Work Cited}

Embree, Lester. Reflective Analysis: A First Introduction to Phenomenology. Bucharest: Zeta Books, 2006. 